\title{
Rupture of the cervix during prostaglandin termination of pregnancy
}

\author{
E. K. EL-ETRIBY \\ M.D., M.R.C.O.G. \\ E. DAW \\ M.R.C.O.G.
}

North Manchester General Hospital, Crumpsall, Manchester

\begin{abstract}
Summary
A case of uterine rupture following extra-amniotic prostaglandin $E_{2}$ with a subsequent obstetrical complication is reported.
\end{abstract}

\section{Introduction}

Uterine rupture as a complication of therapeutic mid-trimester abortion has been reported with prostaglandins administered by the intravenous, intra-amniotic and extra-amniotic routes (Traub and Ritchie, 1979). Although it remains rare, nevertheless it is sometimes fatal.

Rupture of the uterus following prostaglandininduced therapeutic abortion is usually of the cervix, although other sites have been described (Emery, Jarvis and Johnson, 1979). Lateral and anterior ruptures have been reported (Kajanoja et al., 1974) but posterior tears are commonest (Kajanoja et al., 1974; Wentz, Thompson and King, 1973; Burkman et al., 1976).

Previous reports have described excessive blood loss when hysterectomy was necessary to control the loss. The present authors report a case of uterine rupture following extra-amniotic prostaglandin $E_{2}$, where repair was effected but in which a further rupture occurred during a subsequent pregnancy.

\section{Case history}

When 17 years old, this patient had a therapeutic termination of her first pregnancy at 16 weeks of gestation. Extra-amniotic prostaglandin $\mathrm{E}_{2}$ together with intravenous syntocinon was given for $36 \mathrm{hr}$ before expulsion of the products. Excessive vaginal bleeding then prompted examination, when a 3-4 $\mathrm{cm}$ longitudinal posterior cervical laceration was found. This was repaired under general anaesthesia with interrupted chromic catgut sutures. The overall blood loss was $200 \mathrm{ml}$ and blood transfusion was not necessary. The patient made an uneventful recovery and there was no fistula when she was examined at the follow-up clinic. The patient was next seen, 2 years later, in labour, when $\mathbf{3 8}$ weeks pregnant, having had no antenatal care. On examination a closed cervical os was found and a posterior cervical rupture $5 \mathrm{~cm}$ long. Emergency Caesarean section was performed and a live female infant was born. The laceration was again repaired.

\section{Discussion}

As each method for inducing abortion has been introduced there have followed reports of associated uterine damage. Berk, Ullman and Berger (1971) described 2 instances of the fetus being extruded through a laceration of a posterior uterine sacculation in the absence of cervical dilatation following intra-amniotic hypertonic saline. Gordon (1972) reported a transverse laceration of the posterior fornix resulting in cervico-vaginal fistula, associated with intra-amniotic hypertonic saline and Goodline et al. (1972) described 4 further cases, only one of which was recognized at the time of abortion. Severe cervical damage after intra-amniotic urea and prostaglandin $F_{2} \alpha$ (Watson, Beard and Craft, 1972) and cases of cervical rupture after intraamniotic prostaglandin $F_{2}$ have been described (Wentz et al., 1973; Kajanoja et al., 1974). Burkman et al. (1976) had 6 cases using intra-amniotic prostaglandin and urea. Similarly both cervical and uterine rupture have been noted after intra-amniotic prostaglandin $F_{2}$ and hypertonic saline (Borten and Friedman, 1978; Emery et al., 1979). Lowensohn and Ballard (1974) thought that $1 \%$ of terminations using intra-amniotic prostaglandin alone resulted in cervico-vaginal fistula.

It was hoped that the introduction of prostaglandin to induce abortion by the extra-amniotic route would reduce such side effects, but rupture of the uterus after extra-amniotic prostaglandin $E_{2}$ and intravenous syntocinon have been reported (Traub and Ritchie, 1979). A similar rupture is reported from the present case, but this was repaired only to recur in a subsequent spontaneous labour.

\section{References}

Berk, E., Ullman, J. \& Berger, J. (1971) Experience and complications with the use of hypertonic intra-amniotic saline solution. Surgery, Gynecology and Obstetrics, 133, 955. 
Borten, M. \& Friedman, E.A. (1978) Uterine rupture: a complication of mid-trimester abortion. Prostaglandins, 15, 187.

Burkman, R.T., Atienza, M.F., King, T.M. \& BurnetT, L.S. (1976) Intra-amniotic urea and prostaglandin $F_{2}$ alpha for mid-trimester abortion. American Journal of Obstetrics and Gynecology, 126, 328.

EMERY, S., JARvis, G.J. \& JohnSON, D.A.N. (1979) Uterine rupture after intra-amniotic injection of prostaglandin $\mathrm{E}_{2}$. British Medical Journal, 2, 51.

Goodline, R., Newell, J., O'Hare, J. \& Sturz, H. (1972) Cervical fistula; a complication of mid-trimester abortion. Obstetrics and Gynecology, 40, 82.

GoRDoN, R.T. (1972) Cervical vaginal fistula as a result of saline abortion. American Journal of Obstetrics and Gynecology, 112, 578.

Kajanoja, P., Jungner, G., Widholm, O., Karjalainon, 0. \& Seppala, M. (1974) Rupture of the cervix in prosta- glandin abortion. Journal of Obstetrics and Gynaecology of the British Commonwealth, 81, 242.

Lowensohn, R. \& Ballard, C.A. (1974) Cervico-vaginal( fistula: an apparent increased incidence with prostaglandin $\mathrm{F}_{2}$ alpha. American Journal of Obstetrics and Gynecology:119, 1057.

Shearman, R., Smith, I. \& Korda, A. (1972) In: Prostaglandin Clinical applications in Human Reproduction; p. 443. (Ed by Southern, R.P.) Futura Publications, New York. 흐

TRAUB, A.I. \& RITCHIE, J.W.K. (1979) Rupture of the uteruss during prostaglandin-induced abortion. British Medica扁 Journal, 2, 496.

Watson, P.J.B., BeaRd, R.J. \& CRAFT, L. (1973) Injuries tọ the cervix after induced mid-trimester abortion. Journal of Obstetrics and Gynaecology of the British Commonwealth, 0 80, 284.

Wentz, A.C., Thompson, B.H. \& King, T.M. (1973) Ex $\vec{\omega}$ perience with intra-amniotic prostaglandin $F_{2}$ alpha. American Journal of Obstetrics and Gynecology, 117, 513. 